\section{Research on Plantar Fasciitis}

\author{
Qing Yang' and Jianying Zhang ${ }^{2 *}$ \\ 'Department of Anesthesiology, HSHS Medical Group, St John's Hospital, \\ 800 E. Carpenter Street, Springfield, IL 62704, USA
}

${ }^{2}$ MechanoBiology Laboratory, Department of Orthopaedic Surgery, University of Pittsburgh School of Medicine, E1640 BST, 200 Lothrop Street, Pittsburgh, PA 15213, USA

\begin{abstract}
The plantar fascia is a ligament connecting the heel bone to the toes and is constantly subjected to mechanical loads during daily activities. Despite being one of the most common foot diseases in orthopedics, the mechanism of plantar fasciitis remains largely unknown and there is no effective treatment. The structure of human plantar fascia is different from that of other animals because humans are bipeds; thus, there is no suitable animal model. In this review, we summarize the current research on the structural components of human plantar fascia, discuss its cellular properties, and introduce treatment approaches for plantar fasciitis. Finally, we conclude by sharing our perspective on existing challenges and future directions for new treatments.
\end{abstract}

\section{Introduction}

The Plantar Fascia (PF) is a flat band of ligament-like tissue that connects the calcaneus to the metatarsals. Sustaining the body weight during daily activities, PF is constantly subjected to mechanical loading [1]. During activities like walking and running, the mechanical load on PF can be several folds the body weight [2]. PF is easily injured in its functional capacity. Plantar fasciitis is commonly found among the physically active population and affects more than 3 million people in the United States every year [3]. However, there is no effective treatment because its pathogenesis is largely unknown [4]. While PF has been extensively studied biomechanically, little has been done at the structural and cellular levels because of the structural differences between the human PF and that of other animals such as mice, rats,

*Corresponding author: Jianying Zhang, MechanoBiology Laboratory, Department of Orthopaedic Surgery, University of Pittsburgh School of Medicine , 210 Lothrop St., BST, E1640, Pittsburgh, PA, 15213, Tel: +1 4123835302; Fax: +1 4126488548; E-mail: jianying@pitt.edu

Citation: Yang Q, Zhang (2020) Research on Plantar Fasciitis. J Stem Cell Res Dev Ther 6: 047.

Received: July 29, 2020; Accepted: August 24, 2020; Published: August 31, 2020

Copyright: (C) 2020 Yang Q, et al. This is an open-access article distributed under the terms of the Creative Commons Attribution License, which permits unrestricted use, distribution, and reproduction in any medium, provided the original author and source are credited. rabbits, goats, and birds. More important reason is that humans are bipeds [5]. This review covers the current research on plantar fasciitis including the structure of PF, the cellular and molecular mechanisms of pathogenesis, the role of mechanical loading, clinical approaches to treatment, and areas in need of future investigation.

\section{Structural Components of the Plantar Fascia}

Anatomical studies of human plantar fascia have been done by several groups $[6,7]$. Human PF is a pearly white, glistening layer of fiberous bundles measuring a few millimeters in thickness. The ligament-like tissue firmly joins the plantar muscles and skin [7]. On average, the widths of PF are 2 and $6 \mathrm{~cm}$ at the proximal and distal ends, respectively. Its length is $12 \mathrm{~cm}$ from the medial tuberculum to the metatarsophalangeal joint $[6,7]$.

Structural details of human PF have been published recently [1]. Our results showed that human PF consists of two different kinds of tissues: on the outside is a loose mesh-like "sheath" (PF-S) that surrounds the inner "core" made of dense and tight collagen bundles (Figure 1). Scanning Electron Microscope (SEM) images showed that the diameter of collagen fibers in the sheath is thinner than those in the core $(61.3 \pm 8.5 \mathrm{~nm}$ vs. $89.5 \pm 9.2 \mathrm{~nm})$ (Figure 2).

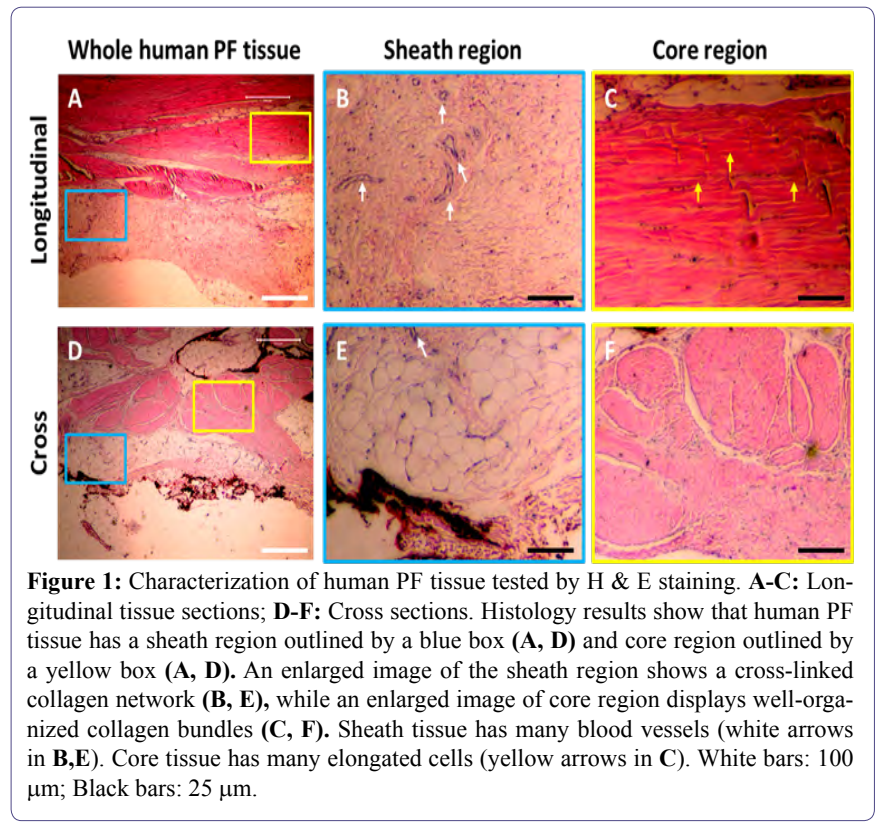

The sheath and core differ on cellular and protein composition as well. PF-S has less type I collagen and more type IV collagen (Figure 3 ) when compared to PF-C [1]. Some blood vessel-like tissues are also found in sheath with positively stains for CD31 and CD34 (Figure 4) [1]. In addition, the sheath contains elastic fibers and hyaluronanas shown by Gieson stain and Alcian blue [7]. 


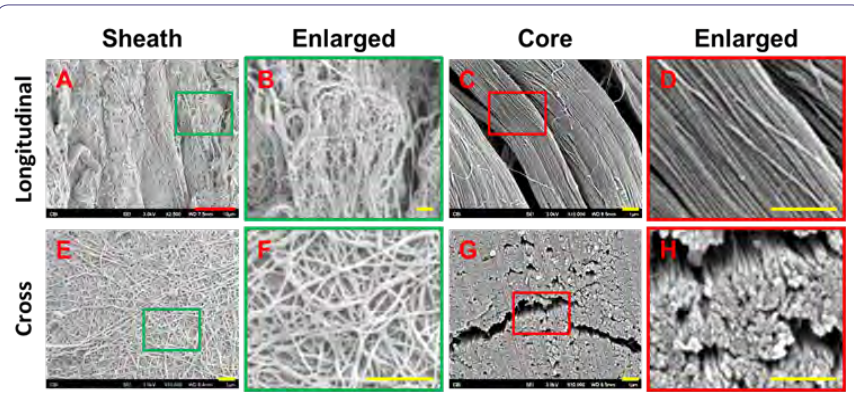

Figure 2: Characterization of human PF tissue tested by Scanning Electron Microscope (SEM). A-D: Longitudinal tissue sections; E-H: Cross sections. SEM images show that human PF tissue has loose net-like mesh of sheath region outlined by a green box (A, B, E, F) and high-density collagen fiber bundles are found in core region outlined by a red box $(\mathrm{C}, \mathrm{D}, \mathrm{G}, \mathrm{H})$. The enlarged images of the sheath and core tissues show the diameter of collagen fibers in the sheath is thinner than that in the core tissues. Red bar: $10 \mu \mathrm{m}$; Yellow bars: $1 \mu \mathrm{m}$.

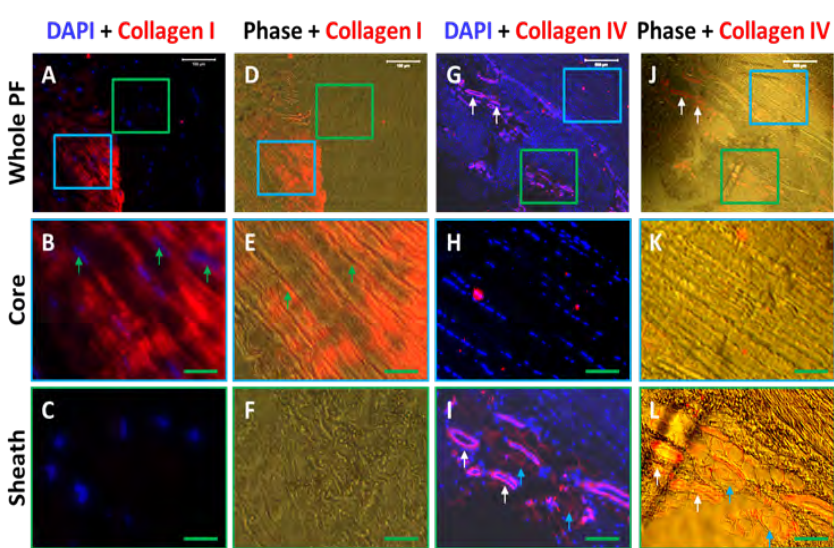

Figure 3: Immunostaining and phase images show differential expression of collagen type I and type IV in the sheath and core tissues of human PF. A-F: Collagen I staining; G-L: Collagen IV staining. The results show that the sheath tissue of human PF tissue has a cross-link net-like mesh structure negatively stained by collagen type I (green box areas in A, C, D, F). Enlarged images of the blue box areas show elongated cells stay in well-organized collagen fiber bundles (green arrows in $\mathbf{B}, \mathbf{E}$ ) positively stained with collagen type I (red fluorescence in $\mathbf{A}, \mathbf{B}, \mathbf{D}, \mathbf{E}$ ). In another hand, the sheath tissue has many blood vessel-like tissues (white arrows in $\mathbf{G}, \mathbf{J}, \mathbf{I}, \mathbf{L}$ ) positively stained with collagen type IV (red fluorescence in $\mathbf{G}, \mathbf{J}, \mathbf{I}, \mathbf{L}$ ). Enlarged images of blue box areas are negatively stained by collagen type IV $(\mathbf{G}, \mathbf{J}, \mathbf{H}, \mathbf{K})$. White bars: $100 \mu \mathrm{m}$; Green bars: $25 \mu \mathrm{m}$.

\section{Characterization of Human PF Cells}

Few studies to date focus on biological properties of the cells in $\mathrm{PF}$ [1]. There are several different cell populations in human PF. The cells isolated from sheath tissue (PF-S cells) have a cobblestone-like shape, while the cells isolated from core tissue ( $\mathrm{PF}-\mathrm{C}$ cells) maintain an elongated shape (Figures 5A, 5B). Proliferation testing indicates that PF-S cells grow faster (Figure 5C), produce larger colonies and higher cell numbers than PF-C cells (Figures 5D-5F) [1]. PF-S cells express markers for stem cell (e.g. nucleostemin, Oct-4 and SSEA4) and vascular cell (e.g. CD31 and CD34) and produce collagen IV (Figure 5G, 5I, 5K, 5M, 5O, 5Q). On the other hand, PF-C cells resemble fibroblasts and produce collagen I (Figure 5P). These findings indicate that PF-S cells maintain their "stemness" better than PF-C cells [1]. Studying PF on the cellular level provides the basic scientific data to help understand the mechanisms for developing plantar fasciitis.

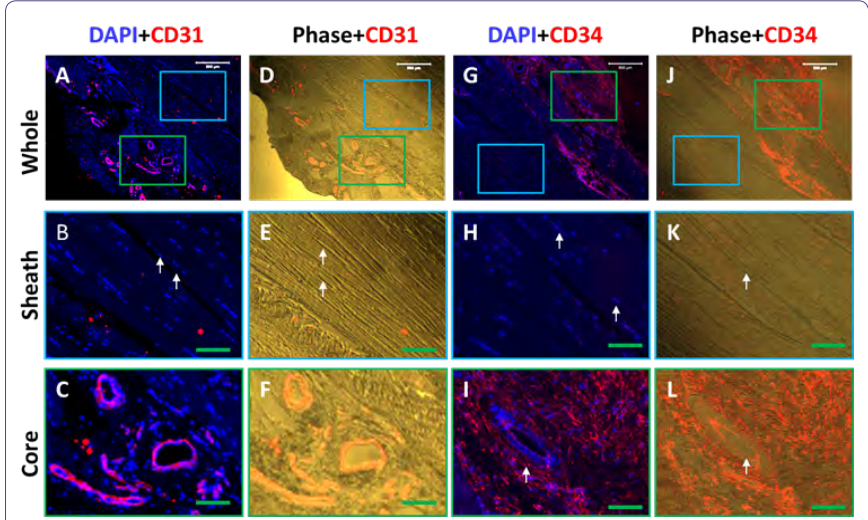

Figure 4: Immunostaining and phase images show much higher expression of endothelial cell markers, CD31 and CD34 in the sheath compared to the core tissues of human PF. The results indicate that the sheath tissue has a cross-link network of collagen fibers with many blood vessel-like tissues positively stained by CD 31 (red fluorescence in $\mathbf{A}, \mathbf{D}, \mathbf{C}, \mathbf{F}$ ) and CD34 (red fluorescence in $\mathbf{G}, \mathbf{J}, \mathbf{I}, \mathbf{L}$ ). Enlarged images of the blue box areas show elongated cells stay in well-organized collagen fiber bundles (white arrows in $\mathbf{B}, \mathbf{E}, \mathbf{H}, \mathbf{K})$ negatively stained with $\mathrm{CD} 31(\mathbf{A}, \mathbf{B}, \mathbf{D}, \mathbf{E})$ and CD34 (G, H, J, K). White bars: $100 \mu \mathrm{m}$; Green bars: $25 \mu \mathrm{m}$.

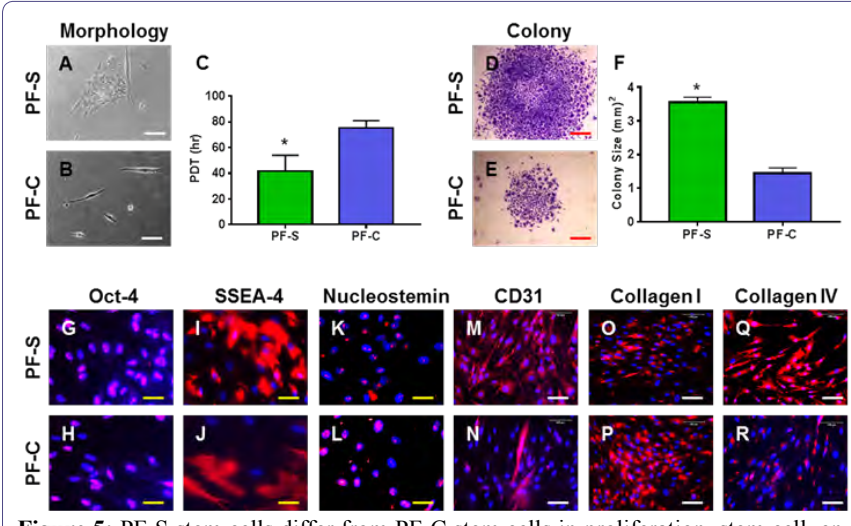

Figure 5: PF-S stem cells differ from PF-C stem cells in proliferation, stem cell, endothelial, and ligament cell marker expression. The morphology of PF-S cells cultured for 7 days shows a typical cobblestone shape consisting of many cells (A). In contrast, the morphology of PF-C cells cultured for 7 days shows elongated shape with very few cells (B). Population doubling time (PDT) indicates that PF-S cells grow much faster than PF-C cells (C). Moreover, PF-S stem cells form larger colonies than PF-C stem cells $(\mathbf{D}, \mathbf{E}, \mathbf{F})$. Furthermore, PF-S exhibit more extensive expression of stem cell markers compared to PF-C stem cells (G-L). PF-S cells express significantly higher levels of CD31 (endothelial cell marker) and collagen type IV (membrane cell marker), but lesser collagen type I (ligament cell marker) than PF-C (M-R). White bars: 100 $\mu \mathrm{m}$; Red bars: $500 \mu \mathrm{m}$; Yellow bars: $25 \mu \mathrm{m}$.

\section{Biomechanics of the Plantar Fascia}

The biomechanical features of the plantar fascia have been well studied $[6,8,9]$. Traditionally, human joint kinematics is analyzed using a link-segment model [10]. However, this approach cannot be adapted to the intrinsic foot structures [11]. Using improved camera and computer technology, multi-segment foot models have been developed [12]. The biomechanical behavior of the medial, middle and lateral PF regions has been investigated [13]. The elastic modulus is the greatest at the lateral PF component (1560 MPa), followed by the middle (1100MPa), middle-lateral (714 MPa), and medial (701 $\mathrm{MPa}$ ). A biomechanical model has been used to calculate the load bearing characteristics of the plantar fascia and determine the effect 
of cutting the plantar fascia on the stiffness of the foot. With a load of $683 \mathrm{~N}$ applied to the foot, the model predicts a $17 \%$ increase in vertical displacement and a $15 \%$ increase in horizontal elongation when the plantar fascia was cut, compared to when the plantar fascia was intact [14].

Similarly, a computational model for analysis of the structural behavior of the human foot during standing has been used to investigate the biomechanical effects of releasing the plantar fascia [15]. This model has been successfully validated by comparing its resultant ground reactions with foot-ground pressure measurements and its predicted displacements with those observed in radiological tests. Total fascia release causes extensive arch deformation during standing, exceeding normal deformation by more than $2.5 \mathrm{~mm}$ [15]. Simultaneously, the tension stress carried by the long plantar ligaments increases to more than $200 \%$ of the normal average stress [15]. These findings indicate that the plantar fascia plays an important role in the foot load-bearing ability, and plantar fascia release must be very carefully considered [16]. More mechanical studies have corroborated that operative procedures may pose a risk to arch stability and clinically may produce dorsolateral midfoot pain $[17,18]$.

One clinical application of quantitative biomechanical measurements is the evaluation of the running patient [19]. Running injuries can be characterized by kinematic data including stride figures, angle-time graphs, and angle-angle diagrams for the sagittal plane motion of the hip, knee, and ankle joints [19].

A recent study has found that forefoot strike may overload the plantar fascia and impose higher risk of plantar fasciitis by comparing the foot arch deformation and PF tension between different foot strike techniques in running using computational models [9]. Forefoot strike increases stress on the plantar connective tissue by $18.28-200.11 \%$ and PF tensile force by $18.71-109.10 \%$. These findings suggest that forefoot strike runners are more vulnerable to plantar fasciitis [9].

Since plantar fascia maintains the foot arch structure and absorbs dynamic foot contact loading during human locomotion, excessive stretching, repetitive and abnormal stress can induce plantar fascia injury. A study has shown that mechanical overloading on plantar fascia during daily walking could make fascia more stressed and might cause acute or even chronic inflammation [20]. However, the effect of mechanical overloading on cellular changes is not well studied. We have investigated the mechanobiological responses of human PF stem cells using an in vitro cell stretching model [1]. The results have shown that Moderate Mechanical Stimulation (MMS) at $4 \%$ stretching did not enhance collagen I expression in PF-S cells but did increase it significantly in PF-C cells (Figure 6A). Moreover, Intensive Mechanical Stimulation (IMS) at $8 \%$ stretching enhances collagen I expression in both types of PF stem cells (Figure 6A). Furthermore, MMS induces collagen IV expression significantly in PF-S stem cells (Figure 6B), but not in PF-C stem cells (Figure 6B). IMS increases the expression of collagen IV in both PF-S and $\mathrm{PF}-\mathrm{C}$ cells with higher expression in PF-S stem cells compared to PF-C cells and un-stretched control cells (Figure 6B). MMS does not increases angiogenesis gene CD105 expression in both PF-S and PF-C cells, but IMS increases CD105 expression in PF-S cells (Figure 6C). MMS does not enhance non-ligament-related gene expression including lipoprotein lipase (LPL) for adipocytes (Figure 6D), Runx2 for osteocytes (Figure 6E), and collagen II for chondrocytes (Figure $6 \mathrm{~F})$ in both PF-S and PF-C stem cells. However, IMS increases all three non-ligament-related genes in both PF-S and PF-C stem cells [1].

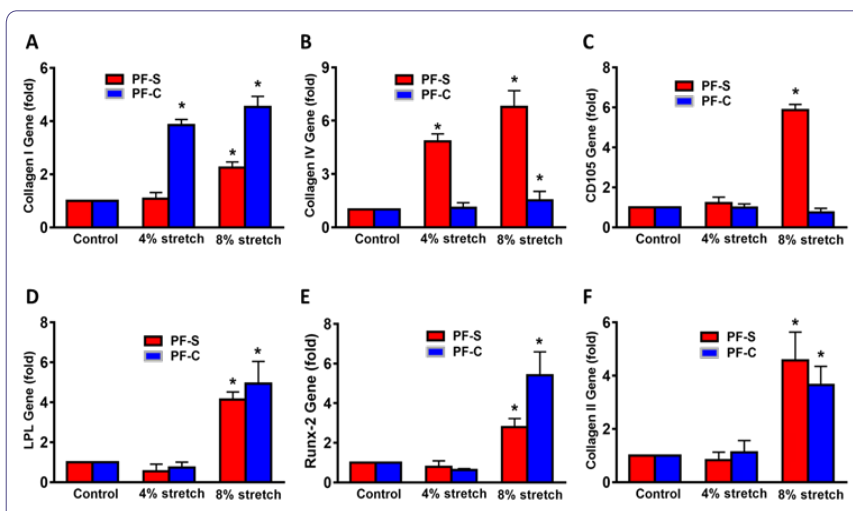

Figure 6: Mechanical loading induces differential gene expression in PF-S stem cells and PF-C stem cells. Moderate mechanical stimulation (MMS) at $4 \%$ stretching does not alter collagen expression in PF-S stem cells, but MMS significantly increases collagen I expression in PF-C stem cells (A). However, intensive mechanical stimulation (IMS) at $8 \%$ stretching enhances collagen I expression in both types of stem cells (A). In contrast, MMS induces collagen IV expression significantly in PF-S stem cells, but not in PF-C stem cells (B). IMS increases the expression of collagen IV in both PF-S and PF-C stem cells with higher expression in PF-S stem cells compared to PF-C cells and un-stretched control cells (B). Moreover, MMS does not increase angiogenesis marker, CD105 expression in both PF-S and PF-C stem cells, but IMS increases CD105 expression in PF-S stem cells (C). MMS does not enhances non-ligament-related gene expression including LPL for adipocytes (D), Runx-2 for osteocytes (E), and collagen II for chondrocytes (F) in both PF-S and PF-C stem cells. However, IMS increases all three non-ligament-related genes in both PF-S and PF-C stem cells.

The study has demonstrated that mechanical overloading increases matrix degradative enzymes of MMP-1 (Figure 7A) and MMP-2 (Figure 7B) in both of PF-S and PF-C stem cells (Figure 7A, 7B). Furthermore, mechanical overloading also enhances inflammatory marker genes of COX-1 (Figure 7C) and COX-2 (Figure 7D) in both of PF-S and PF-C stem cells [1]. These findings indicated that stem cells play an important role in the development of plantar fasciitis.
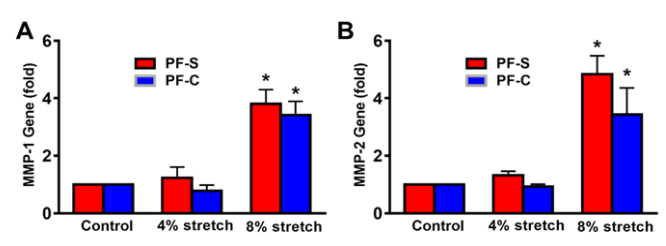

C

D
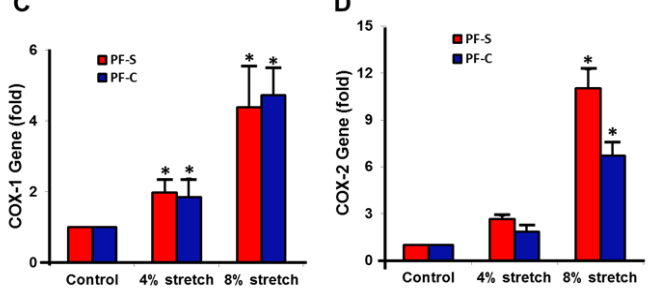

Figure 7: Mechanical loading induces differential gene expression on matrix degradative enzymes (MMP-1, MMP-2) and inflammatory markers (COX-1, COX-2) in PF-S stem cells and PF-C stem cells. Moderate mechanical stimulation (MMS) at $4 \%$ stretching does not alter the expression of MMP-1 (A) and MMP-2 (B) in PF-S and PF-C stem cells, but Intensive Mechanical Stimulation (IMS) at $8 \%$ stretching enhances the expression of MMP-1 (A) and MMP-2 in both types of stem cells (B). Moreover, MMS slightly increases inflammatory marker expression of COX-1 (C), and COX-2 (D) in both PF-S and PF-C stem cells. However, IMS significantly enhances inflammatory gene expression including COX-1 (C), and COX-2 (D) in both PF-S and PF-C stem cells. 
More studies have indicated that in response to mechanical stimulation cells would release bioactivesignal molecules such as interleukins (IL), adhesion kinases and many others. It has been found that mechanical loading of human tendon results in a marked interstitial increase in concentration of various growth factors, and some growth factors such as IGF-1 [21], transforming growth factor (TFG- $\beta$ [22], PDGF [23], IL-1 $\beta$ [24], and IL-6 [25]) can stimulate the synthesis of collagen. However, the signals triggering the plantar fascia stem cells in response to mechanical loading, and the subsequent expression and synthesis of specific extracellular matrix proteins, as well as its coupling to the mechanical function of the PF tissue are only partly described.

\section{Plantar Fasciitis Treatments}

Plantar fasciitis is the most common cause of chronic pain beneath the heel in adults. About $10 \%$ of people develop plantar fasciitis during their lifetime [3]. However, the etiology of plantar fasciitis is not well understood [26,27]. Traditionally, clinicians have thought that mechanical overload plays a major role in the development of plantar fasciitis but the mechanism itself remains unclear [28]. The collagen degeneration seen in plantar fasciitis is similar to the chronic necrosis of tendinosis, featuring loss of collagen continuity and increases in ground substance and vascularity [29]. Some researchers have shown that when PF is exposed to abnormal levels of stress bilaterally, such as during an unaccustomed activity, with prolonged standing or by wearing inappropriate footwear, micro-damage to the PF accumulates and overtime degenerative change ensues [30,31].

Currently, there are two options for treating plantar fasciitis. First option is non-operative, including rest, weight loss, ice packs, deep massage, shoe inserts [29], heel cups [32], night splint, antiinflammatory drugs [33], extracorporeal shock wave therapy [34], and plantar fascia stretching exercises [35]. Second is surgery [36].

Rest is one of the most commonly used treatments for plantar fasciitis. However, only $25 \%$ of patients experience effective improvement after resting, suggesting that it does not conduce healing [37].

Stretching is another important approach [38]. Studies on the effects of stretching have yielded conflicting results [39]. One study has reported successful improvements in heel pain in $83 \%$ of patients [37]. In another study, a two-week stretching program has failed to provide statistically significant benefit in foot pain, foot function, or general foot health [40]. Some improvements on stretch reflex activity and clinical outcomes have been shown with counter-strain [41]. In a pilot study using static progressive stretch brace to treat pain and functional limitations in the patients with plantar fasciitis, the brace has become an viable alternative to stretching exercises [42]. A systematic review paper has shown that stretching improved both pain and function subjectively, but when compared to other interventions, including sham treatment, no statistically significant benefit was observed [39].

Medications including Nonsteroidals Anti-Inflammatory Drugs (NSAIDs) and steroids are also used for plantar fasciitis. Although NSAIDs may increase pain relief and decrease disability in patients with plantar fasciitis [32], they confer substantial side effects including gastrointestinal bleeding, gastric pain and renal damage [43].
Steroid injection is a common treatments for plantar fasciitis, with a success rate for pain relief of more than $70 \%[44,45]$. In a study of 65 patients treated with corticosteroid versus a placebo, the subjective pain scores in the corticosteroid group has been significantly higher than the placebo group at 6 weeks and the effect can persist for up to 12 weeks [46]. However, others warn that steroid treatment may cause plantar fascia rupture [47].

Platelet Rich Plasma (PRP) is an autologous blood product in which the platelets have been concentrated. In the recent years, PRP has been used to promote wound healing since it is rich in cytokines, growth factors, chemokines, and fibrin scaffolds [48]. The normal concentrations of platelets in whole blood are $1.5 \times 10^{5}$ platelets $/ \mathrm{ml}$ to $3.5 \times 10^{5}$ platelets $/ \mathrm{ml}$, while the concentration of platelets in PRP at least is $1 \times 10^{6} / \mathrm{ml}$ [49]. The use of PRP as a supplement of cell culture media has consistently shown to potentiate stem cell proliferation, migration, and differentiation [50]. In vivo, platelets are activated at the site of injury where they participate in haemostasis, promoting tissue repair, including revascularization [51]. Although PRP has been used in surgery for 3 decades, there has been a recent interest in the use of PRP for the treatment of tendon and ligament injuries [49]. A clinical study has been performed in 50 patients with plantar fasciitis by PRP injection treatment. The results showed that mean pain severity improvement was $45 \%$ at 6 months with almost two in three patients reporting satisfaction with the treatment [52]. Similar outcomes with patient satisfaction rates of $79-96 \%$ have been reported [53,54]. The clinical findings indicated that PRP is a safe alternative with the potential to decrease the pain in plantar fasciitis [53]. A systematic review has demonstrated statistically significant improvements in terms of FAAM score (Foot and Ankle Ability Measure), Foot-SANE (Foot-Single Assessment Numeric Evaluation), SF-12-v2 (Short Form 12 item Health Survey version 2) after 32 weeks for 22 patients with chronic plantar fasciitis receiving a single PRP injection [55]. A meta-analysis shows that PRP treatment has better long-term efficacy in relieving pain than steroid injections $[56,57]$.

The positive extensive clinical experience with PRP in different medical areas has prompted researchers to explore clinical opportunities for optimized PRP therapies [58]. Clinically, when nonoperative treatment for chronic plantar fasciitis fails, often a corticosteroid injection is given. Corticosteroid injection gives temporary pain reduction but no healing [59]. A study has been done in 115 patients with chronic plantar fasciitis treated either with PRP injection or corticosteroid injection. The treatment of patients with chronic plantar fasciitis with PRP seems to reduce pain and increase function more as compared with the effect of corticosteroid injection [59].

Overall, these results indicated that PRP has a great potential in clinical applications. Nevertheless, more scientific research with well design studies and large samples sized will have to conclude PRP effectiveness before it is more widely covered [50].

Extracorporeal shock wave therapy has been used to treat various musculoskeletal disorders including plantar fasciitis. Shock waves promote angiogenesis of PF leading to tissue regeneration [60]. Although laser irradiation is also used to treat plantar fasciitis, its efficacy is questionable [61]. Ultrasound is a high frequency sound wave used to treat injured tendons and ligaments. When comparing different modalities, high-intensity focused extracorporeal shock wave has superior pain-relieving effects at 2 to 4 months, while ultrasound- 
guided pulsed radiofrequency treatment and intracorporeal pneumatic shock therapy have superior effects at 6 to 12 months. Only radial extracorporeal shock wave therapy induced significant pain reduction compared to placebo at 0 to 6 weeks [62].

When conservative treatment and time fail, surgical intervention may be necessary. In a case report, surgery is used as an adjunct for a patient with plantar fasciitis, who has remained pain free and returned to running at 10 months after the procedure [63]. Open plantar fascia release is the most traditional operative method. However, surgery has several drawbacks, including large wound, longer postoperative recovery time, and potential occurrence of complex regional pain syndrome. Although plantar fascia release under arthroscopy can minimize the wound, the postoperative satisfaction rate remains haphazard at $50-95 \%[64,65]$. In order to reduce the risk of skin healing problems, nerve disturbance, infection and persistent pain associated with a prolonged recovery time, new surgical procedures are under development [66].

Although most patients respond well to conservative treatments and/or surgery, some still experience on-going pain after exhausting all available options. Newer experimental treatments involve human placental membrane and other types of point-care allografts, which are now commercially available. A successful case has been reported in a patient with chronic plantar fasciitis for whom both conservative therapies and surgery failed. After the implantation of viable intact cryopreserved human placental membrane, the patient has regained function and resumed working full time [67].

\section{Conclusion and Future Directions}

Enhancing plantar fasciitis healing remains one of the greatest challenges in orthopedic research. The quality of existing publications on plantar fasciitis is weak due to the lack of a suitable animal model. Although plantar fasciitis is the most common disease in orthopedics ( $10 \%$ life time prevalence), its cellular molecular mechanism is largely unknown. In recent years, the importance of adult stem cells in tissue regeneration and degeneration has been noted and better understanding of the pathogenesis of plantar fasciitis at the cellular level is to be desired. To date, only one paper has studied the cellular structure and composition of human PF [1].

Advances in stem cell-based therapeutic approaches have shown great potential for tissue repair and regeneration. However, there is no research articles focused on stem cell based therapy for plantar fasciitis. Although some clinical medical doctors have anecdotally injected autologous bone marrow stem cells (BMSCs) to treat plantar fasciitis (Blutail Medical Group; https://www.bluetailmedicalgroup. $\mathrm{com} /$ services/plantar-fasciitis), clinical data regarding its efficacy is limited.

The literature show that there are many challenging questions to be answered and both basic and translational studies are needed before stem cell based therapies can be recommended as a routine clinical treatment for plantar fasciitis. Plantar fasciitis is manifested as plantar fascia inflammation and degeneration, for which mechanical overloading is considered as the major causative factor [68]. However, the underlying cellular and molecular mechanisms remain unclear. Our previous studies have found that mechanical overloading plays an important role in the development of tendinopathy [69]. We have found that mechanical overloading induces tendinopathy development by initiation of tendon inflammation via HMGB1, leading to eventual tendon degeneration [69]. However, whether HMGB1 mediates plantar fasciitis development due to mechanical overloading is largely unknown. Our previous studies have shown that mechanical overloading on the stem cells of tendon and plantar fascia produces abnormally high levels of Cycloxygenease-2 (COX2) and prostaglandin $\mathrm{E}_{2}\left(\mathrm{PGE}_{2}\right)[1,69]$. Such an increase in PGE2 and COX-2 levels not only elicits tendon/ligament inflammation, but also induces aberrant differentiation of tendon/ligament stem cells to nontenocyte phenotypes. Within tendon/ligament, this inflammation and aberrant differentiation often lead to degeneration of tendon/ligament tissues characterized by hypercellularity, angiogenesis, and abnormal arrangement of collagen fibers $[70,71]$. These findings indicated that severe pain in plantar fasciitis may be mediated by the abnormal levels of proinflammatory mediators that are released under excessive mechanical loading. Thus, the future study should focus on the PF stem cells that response to mechanical overloading.

It is important to identify what cell populations (PF-S or/and PF-C stem cells) are involved in PF regeneration and degeneration. Our previous study has found that the stem cells isolated from the sheath of plantar fascia (PF-S cells) have more "stemness" than the stem cells isolated from the core of plantar fascia (PF-C cells).PF-S stem cells maintain "stemness" better than PF-C stem cells after long term culture. Both PF-S and PF-C cells are capable of differentiating into adipocytes, osteocytes and chondrocytes, but the extent of PF-S stem cell differentiation is significantly higher than that of PF-C stem cells [1]. The study on proliferation and differentiation of PF stem cells with various mechanical treatments can provide the first evidence for understanding the mechanisms of plantar fasciitis development.

Stem cells have multi-differentiation potential, can transdifferentiated into other types of cells, and have emerged as frontline regenerative medicine source in recent times, for reparation of tissues and organs anomalies occurring due to congenital defect, disease, and age associated effects [72]. It is believed that stem cells play a vital role in tissue regeneration and repair. Stem cell transplantation has been used to heal large bone defects, bad burns, spinal cord injuries, heart damage, worn joints, nerve damage, and Parkinson's disease. Recent advances in adult stem cell research offers a promising advanced alternative for stem cell transplantation [73]. An adult stem cell is thought to be an undifferentiated cell among differentiated cells in a tissue or organ. The adult stem cell can renew itself and can differentiate to some specialized cell type of the tissue or organ. If the differentiation of adult stem cells can be controlled, the adult stem cells may be a good stem cell source for autologous transplantation. Stem cells used in regenerative medicine include Embryonic Stem Cells (ESCs), Umbilical Cord Stem Cells (UCSCs), Bone Marrow Stem Cells (BMSCs), and some tissue and organ-derived adult stem/progenitor cells [74]. Currently, the most clinical stem cells used for wound healing and tissue regeneration were bone marrow stem cells (BMSCs) and adult stem cells. Although stem cells have been successfully used for tendon and ligament repair, which sources of stem cells (bone marrow stem cells or PF stem cells) care most promising or have the best potential to be used for plantar fasciitis remain unknown.

Further study should also identify what type of injury or disease in $\mathrm{PF}$ (such as plantar fascia rupture or chronic plantar fasciitis) requires the implantation of stem cells. The properties of the PF stem cells at 
different stages of plantar fascia disorder are different. It is important to identify whether biologics such as stem cell-derived extracellular matrix replicate the therapeutic effect of stem cells. To address these issues, there is an urgent need to find a suitable animal model used for plantar fasciitis study. Mouse treadmill running model is a good approach for tendinopathy study [69]. Although the structure of human plantar fascia is different from that of other animals because humans are bipeds; the effect of mechanical overloading on plantar fasciitis may be investigated by mouse treadmill running model. Future study should focus on the mechanisms underlying the roles stem cells in $\mathrm{PF}$ degeneration and regeneration using cell culture model, and to establish standard methodologies and treatment protocols for plantar fasciitis.

\section{Acknowledgement}

This work was supported by Albert B. Ferguson, Jr., M.D.Orthopaedic Fund (AD2019-105569), University of Pittsburgh.

\section{References}

1. Zhang J, Nie D, Rocha JL, Hogan MV, Wang JH (2018) Characterization of the structure, cells, and cellular mechanobiological response of human plantar fascia. J Tissue Eng 9: 2041731418801103.

2. Scott SH, Winter DA (1990) Internal forces of chronic running injury sites. Med Sci Sports Exerc 22: 357-369.

3. Riddle DL, Pulisic M, Pidcoe P, Johnson RE (2003) Risk factors for Plantar fasciitis: A matched case-control study. J Bone Joint Surg Am 85: 872877.

4. Lemont H, Ammirati KM, Usen N (2003) Plantar fasciitis: A degenerative process (fasciosis) without inflammation. J Am Podiatr Med Assoc 93: 234-237.

5. Thorpe SK, Holder RL, Crompton RH (2007) Origin of human bipedalism as an adaptation for locomotion on flexible branches. Science 316: 13281331.

6. Chen DW, Li B, Aubeeluck A, Yang YF, Huang YG, et al. (2014) Anatomy and biomechanical properties of the plantar aponeurosis: A cadaveric study. PloS one 9: e84347.

7. Stecco C, Corradin M, Macchi V, Morra A, Porzionato A, et al. (2013) Plantar fascia anatomy and its relationship with Achilles tendon and paratenon. J Anat 223: 665-676.

8. Clark RA, Franklyn-Miller A, Falvey E, Bryant AL, Bartold S, et al. (2009) Assessment of mechanical strain in the intact plantar fascia. Foot (Edinb) 19: 161-164.

9. Chen TL, Wong DW, Wang Y, Lin J, Zhang M (2019) Foot arch deformation and plantar fascia loading during running with rearfoot strike and forefoot strike: A dynamic finite element analysis. J Biomech 2019, 83: 260-272.

10. Reinschmidt C, van den Bogert AJ, Nigg BM, Lundberg A, Murphy N (1997) Effect of skin movement on the analysis of skeletal knee joint motion during running. J Biomech 30: 729-732.

11. Kidder SM, Abuzzahab FS Jr, Harris GF, Johnson JE (1996) A system for the analysis of foot and ankle kinematics during gait. IEEE Trans Rehabil Eng 4: 25-32.

12. Leardini A, O'Connor JJ, Catani F, Giannini S (1999) Kinematics of the human ankle complex in passive flexion; A single degree of freedom system. J Biomech 32: 111-118.
13. Guo J, Liu X, Ding X, Wang L, Fan Y (2018) Biomechanical and mechanical behavior of the plantar fascia in macro and micro structures. J Biomech 76: $160-166$

14. Arangio GA, Chen C, Kim W (1997) Effect of cutting the plantar fascia on mechanical properties of the foot. Clin Orthop Relat Res 339: 227-231.

15. Gefen A (2002) Stress analysis of the standing foot following surgical plantar fascia release. J Biomech 35: 629-637.

16. Kim W, Voloshin AS (1995) Role of plantar fascia in the load bearing capacity of the human foot. J Biomech 28: 1025-1033.

17. Cheung JT, An KN, Zhang M (2006) Consequences of partial and total plantar fascia release: a finite element study. Foot Ankle Int 27: 125-132.

18. Cheung JT, Zhang M, An KN (2006) Effect of Achilles tendon loading on plantar fascia tension in the standing foot. Clin Biomech (Bristol, Avon) 21: 194-203.

19. Cavanagh PR (1987) The biomechanics of lower extremity action in distance running. Foot Ankle 7: 197-217.

20. Chen YN, Chang CW, Li CT, Chang CH, Lin CF (2015) Finite element analysis of plantar fascia during walking: A quasi-static simulation. Foot Ankle In 36: 90-97.

21. Abrahamsson SO, Lohmander S (1996) Differential effects of insulin-like growth factor-I on matrix and DNA synthesis in various regions and types of rabbit tendons. J Orthop Res 14: 370-376.

22. Heinemeier K, Langberg H, Olesen JL, Kjaer M (2003) Role of TGF-beta 1 in relation to exercise-induced type I collagen synthesis in human tendinous tissue. J Appl Physiol 95: 2390-2397.

23. Banes AJ, Tsuzaki M, Hu P, Brigman B, Brown T, et al. (1995) PDGF-BB, IGF-I and mechanical load stimulate DNA synthesis in avian tendon fibroblasts in vitro. J Biomech 28: 1505-1513.

24. Chang SH, Mori D, Kobayashi H, Mori Y, Nakamoto H, et al. (2019) Excessive mechanical loading promotes osteoarthritis through the gremlin-1NF-kappaB pathway. Nat Commun 10: 1442.

25. Helge JW, Stallknecht B, Pedersen BK, Galbo H, Kiens B, et al. (2003) The effect of graded exercise on IL-6 release and glucose uptake in human skeletal muscle. J Physiol 546(Pt 1): 299-305.

26. Goff JD, Crawford R (2011) Diagnosis and treatment of plantar fasciitis. Am Fam Physician 84: 676-682.

27. Karabay N, Toros T, Hurel C (2007) Ultrasonographic evaluation in plantar fasciitis. J Foot Ankle Surg 46: 442-446.

28. Wearing SC, Smeathers JE, Urry SR, Hennig EM, Hills AP (2006) The pathomechanics of plantar fasciitis. Sports Med 36: 585-611.

29. Young CC, Rutherford DS, Niedfeldt MW (2001) Treatment of plantar fasciitis. Am Fam Physician 63: 467-474, 477-468.

30. Wearing SC, Smeathers JE, Sullivan PM, Yates B, Urry SR, et al. (2007) Plantar fasciitis: Are pain and fascial thickness associated with arch shape and loading? Phys Ther 87: 1002-1008.

31. Wearing SC, Smeathers JE, Urry SR (2002) A comparison of two analytical techniques for detecting differences in regional vertical impulses due to plantar fasciitis. Foot Ankle Int 23: 148-154.

32. Donley BG, Moore T, Sferra J, Gozdanovic J, Smith R (2007) The efficacy of oral nonsteroidal anti-inflammatory medication (NSAID) in the treatment of plantar fasciitis: A randomized, prospective, placebo-controlled study. Foot Ankle Int 28: 20-23.

33. Salvi AE (2015) Targeting the Plantar Fascia for Corticosteroid Injection. J Foot Ankle Surg 54: 683-685.

34. Dastgir N (2014) Extracorporeal shock wave therapy for treatment of plantar fasciitis. J Res Med Sci 64: 675-678. 
35. Tahririan MA, Motififard M, Tahmasebi MN, Siavashi B (2012) Plantar fasciitis. J Res Med Sci 17: 799-804.

36. Vohra PK, Giorgini RJ, Sobel E, Japour CJ, Villalba MA, et al. (1999) Long-term follow-up of heel spur surgery. A 10-year retrospective study. J Am Podiatr Med Assoc 89: 81-88.

37. Wolgin M, Cook C, Graham C, Mauldin D (1994) Conservative treatment of plantar heel pain: Long-term follow-up. Foot Ankle Int 15: 97-102.

38. McPoil TG, Martin RL, Cornwall MW, Wukich DK, Irrgang JJ, et al (2008) Heel pain--plantar fasciitis: Clinical practice guildelines linked to the international classification of function, disability, and health from the orthopaedic section of the American Physical Therapy Association. J Orthop Sports Phys Ther 38: A1-A18.

39. Sweeting D, Parish B, Hooper L, Chester R (2011) The effectiveness of manual stretching in the treatment of plantar heel pain: a systematic review. J Foot Ankle Res 4: 19.

40. Radford JA, Landorf KB, Buchbinder R, Cook C (2007) Effectiveness of calf muscle stretching for the short-term treatment of plantar heel pain: a randomised trial. BMC Musculoskelet Disord 8: 36.

41. Wynne MM, Burns JM, Eland DC, Conatser RR, Howell JN (2006) Effect of counterstrain on stretch reflexes, hoffmann reflexes, and clinical outcomes in subjects with plantar fasciitis. J Am Osteopath Assoc 106: 547-556.

42. Sharma NK, Loudon JK (2010) Static progressive stretch brace as a treatment of pain and functional limitations associated with plantar fasciitis: a pilot study. Foot Ankle Spec 3: 117-124.

43. McCarthy D (1998) Nonsteroidal anti-inflammatory drug-related gastrointestinal toxicity: definitions and epidemiology. Am J Med 105: 3S-9S.

44. Furey JG (1975) Plantar fasciitis. The painful heel syndrome. J Bone Joint Surg Am 57: 672-673.

45. Kane D, Greaney T, Bresnihan B, Gibney R, FitzGerald O (1998) Ultrasound guided injection of recalcitrant plantar fasciitis. Ann Rheum Dis 57: 383-384.

46. Ball EMA, McKeeman HMA, Patterson C, Burns J, et al. (2013) Steroid injection for inferior heel pain: a randomised controlled trial. Ann Rheum Dis 72: $996-1002$.

47. Acevedo JI, Beskin JL (1998) Complications of plantar fascia rupture associated with corticosteroid injection Foot Ankle Int 19: 91-97.

48. Carter MJ, Fylling CP, Parnell LK (2011) Use of platelet rich plasma gel on wound healing: a systematic review and meta-analysis. Eplasty 11: e38.

49. Foster TE, Puskas BL, Mandelbaum BR, Gerhardt MB, Rodeo SA (2009) Platelet-rich plasma: from basic science to clinical applications. Am J Sports Med 37: 2259-2272.

50. da Silva Santos SCN, Sigurjonsson OE, de Almeida Custodio C, da Luz Mano JFC (2018) Blood Plasma Derivatives for Tissue Engineering and Regenerative Medicine Therapies. Tissue Eng Part B Rev 24: 454-462.

51. Golebiewska EM, Poole AW (2015) Platelet secretion: From haemostasis to wound healing and beyond. Blood Rev 29: 153-162.

52. Kumar V, Millar T, Murphy PN, Clough T (2013) The treatment of intractable plantar fasciitis with platelet-rich plasma injection. Foot 23: 74-77.

53. Martinelli N, Marinozzi A, Carni S, Trovato U, Bianchi A, et al. (2013) Platelet-rich plasma injections for chronic plantar fasciitis. Int Orthop 37: 839-842.

54. Ragab EM, Othman AM (2012) Platelets rich plasma for treatment of chronic plantar fasciitis. Archives of orthopaedic and trauma surgery 132: 1065-1070.

55. Franceschi F, Papalia R, Franceschetti E, Paciotti M, Maffulli N, et al. (2014) Platelet-rich plasma injections for chronic plantar fasciopathy: a systematic review. British medical bulletin 112: 83-95.
56. Yang WY, Han YH, Cao XW, Pan JK, Zeng LF, et al. (2017) Platelet-rich plasma as a treatment for plantar fasciitis: A meta-analysis of randomized controlled trials. Medicine 96: 8475.

57. Ling Y, Wang S (2018) Effects of platelet-rich plasma in the treatment of plantar fasciitis: A meta-analysis of randomized controlled trials. Medicine 97: 12110 .

58. Andia I, Maffulli N (2018) A contemporary view of platelet-rich plasma therapies: moving toward refined clinical protocols and precise indications. Regen Med 13: 717-728.

59. Peerbooms JC, Lodder P, den Oudsten BL, Doorgeest K, Schuller HM, et al. (2019) Positive Effect of Platelet-Rich Plasma on Pain in Plantar Fasciitis: A Double-Blind Multicenter Randomized Controlled Trial. The American journal of sports medicine 47: 3238-3246.

60. Melvin TJ, Tankersley ZJ, Qazi ZN, Jasko JJ, Odono R, et al. (2015) Primary Care Management of Plantar Fasciitis. The West Virginia medical journal 111: 28-32.

61. Basford JR, Malanga GA, Krause DA, Harmsen WS (1998) A randomized controlled evaluation of low-intensity laser therapy: plantar fasciitis. Archives of physical medicine and rehabilitation 79: 249-254.

62. Li X, Zhang L, Gu S, Sun J, Qin Z, et al. (2018) Comparative effectiveness of extracorporeal shock wave, ultrasound, low-level laser therapy, noninvasive interactive neurostimulation, and pulsed radiofrequency treatment for treating plantar fasciitis: A systematic review and network meta-analysis. Medicine 97: 12819

63. Bernhard K, Ng A, Kruse D, Stone PA: Surgical Treatment of Bone Marrow Lesion Associated with Recurrent Plantar Fasciitis: A Case Report Describing an Innovative Technique Using Subchondroplasty((R)). J Foot Ankle Surg 57: 811-815.

64. Davies MS, Weiss GA, Saxby TS (1999) Plantar fasciitis: how successful is surgical intervention? Foot Ankle Int 20: 803-807.

65. Cole C, Seto C, Gazewood J (2005) Plantar fasciitis: evidence-based review of diagnosis and therapy. American family physician 72: 2237-2242.

66. Oliva F, Piccirilli E, Tarantino U, Maffulli N (2017) Percutaneous release of the plantar fascia. New surgical procedure. Muscles, ligaments and tendons journal 7: 338-340.

67. Sun XP, Wilson AG, Michael GM (2018) Open Surgical Implantation of a Viable Intact Cryopreserved Human Placental Membrane for the Treatment of Recalcitrant Plantar Fasciitis: Case Report With Greater than 2-Year Follow-Up Duration. The Journal of foot and ankle surgery 57: 583-586.

68. Stuber K, Kristmanson K (2006) Conservative therapy for plantar fasciitis: a narrative review of randomized controlled trials. The Journal of the Canadian Chiropractic Association 50: 118-133.

69. Zhao G, Zhang J, Nie D, Zhou Y, Li F, et al. (2019) HMGB1 mediates the development of tendinopathy due to mechanical overloading. PloS one 14: 0222369.

70. Jarvinen TA, Kannus P, Maffulli N, Khan KM (2005) Achilles tendon disorders: etiology and epidemiology. Foot and ankle clinics 10: 255-266.

71. Khan MH, Li Z, Wang JH (2005) Repeated exposure of tendon to prostaglandin-E2 leads to localized tendon degeneration. Clinical journal of sport medicine 15: 27-33.

72. Fortier LA (2005) Stem cells: classifications, controversies, and clinical applications. Vet Surg 34: 415-423.

73. Kovacic JC, Harvey RP, Dimmeler S (2007) Cardiovascular regenerative medicine: digging in for the long haul. Cell stem cell 1: 628-633.

74. Mahla RS (2016) Stem Cells Applications in Regenerative Medicine and Disease Therapeutics. Int J Cell Biol 2016: 6940283. 


\section{di

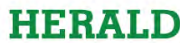

Advances In Industrial Biotechnology | ISSN: 2639-5665

Advances In Microbiology Research | ISSN: 2689-694X

Archives Of Surgery And Surgical Education | ISSN: 2689-3126

Archives Of Urology

Archives Of Zoological Studies | ISSN: 2640-7779

Current Trends Medical And Biological Engineering

International Journal Of Case Reports And Therapeutic Studies | ISSN: 2689-310X

Journal Of Addiction \& Addictive Disorders | ISSN: 2578-7276

Journal Of Agronomy \& Agricultural Science | ISSN: 2689-8292

Journal Of AIDS Clinical Research \& STDs | ISSN: 2572-7370

Journal Of Alcoholism Drug Abuse \& Substance Dependence | ISSN: 2572-9594

Journal Of Allergy Disorders \& Therapy | ISSN: 2470-749X

Journal Of Alternative Complementary \& Integrative Medicine | ISSN: 2470-7562

Journal Of Alzheimers \& Neurodegenerative Diseases | ISSN: 2572-9608

Journal Of Anesthesia \& Clinical Care | ISSN: 2378-8879

Journal Of Angiology \& Vascular Surgery | ISSN: 2572-7397

Journal Of Animal Research \& Veterinary Science | ISSN: 2639-375

Journal Of Aquaculture \& Fisheries | ISSN: 2576-5523

Journal Of Atmospheric \& Earth Sciences | ISSN: 2689-8780

Journal Of Biotech Research \& Biochemistry

Journal Of Brain \& Neuroscience Research

Journal Of Cancer Biology \& Treatment | ISSN: 2470-7546

Journal Of Cardiology Study \& Research | ISSN: 2640-768X

Journal Of Cell Biology \& Cell Metabolism | ISSN: 2381-1943

Journal Of Clinical Dermatology \& Therapy | ISSN: 2378-8771

Journal Of Clinical Immunology \& Immunotherapy | ISSN: 2378-8844

Journal Of Clinical Studies \& Medical Case Reports | ISSN: 2378-8801

Journal Of Community Medicine \& Public Health Care | ISSN: 2381-1978

Journal Of Cytology \& Tissue Biology | ISSN: 2378-9107

Journal Of Dairy Research \& Technology | ISSN: 2688-9315

Journal Of Dentistry Oral Health \& Cosmesis | ISSN: 2473-6783

Journal Of Diabetes \& Metabolic Disorders | ISSN: 2381-201X

Journal Of Emergency Medicine Trauma \& Surgical Care | ISSN: 2378-8798

Journal Of Environmental Science Current Research | ISSN: 2643-5020

Journal Of Food Science \& Nutrition | ISSN: 2470-1076

Journal Of Forensic Legal \& Investigative Sciences | ISSN: 2473-733X

Journal Of Gastroenterology \& Hepatology Research | ISSN: 2574-2566
Journal Of Genetics \& Genomic Sciences | ISSN: 2574-2485

Journal Of Gerontology \& Geriatric Medicine | ISSN: 2381-8662

Journal Of Hematology Blood Transfusion \& Disorders | ISSN: 2572-2999

Journal Of Hospice \& Palliative Medical Care

Journal Of Human Endocrinology | ISSN: 2572-9640

Journal Of Infectious \& Non Infectious Diseases | ISSN: 2381-8654

Journal Of Internal Medicine \& Primary Healthcare | ISSN: 2574-2493

Journal Of Light \& Laser Current Trends

Journal Of Medicine Study \& Research | ISSN: 2639-5657

Journal Of Modern Chemical Sciences

Journal Of Nanotechnology Nanomedicine \& Nanobiotechnology | ISSN: 2381-2044

Journal Of Neonatology \& Clinical Pediatrics | ISSN: 2378-878X

Journal Of Nephrology \& Renal Therapy | ISSN: 2473-7313

Journal Of Non Invasive Vascular Investigation | ISSN: 2572-7400

Journal Of Nuclear Medicine Radiology \& Radiation Therapy | ISSN: 2572-7419

Journal Of Obesity \& Weight Loss | ISSN: 2473-7372

Journal Of Ophthalmology \& Clinical Research | ISSN: 2378-8887

Journal Of Orthopedic Research \& Physiotherapy | ISSN: 2381-2052

Journal Of Otolaryngology Head \& Neck Surgery | ISSN: 2573-010X

Journal Of Pathology Clinical \& Medical Research

Journal Of Pharmacology Pharmaceutics \& Pharmacovigilance | ISSN: 2639-5649

Journal Of Physical Medicine Rehabilitation \& Disabilities | ISSN: 2381-8670

Journal Of Plant Science Current Research | ISSN: 2639-3743

Journal Of Practical \& Professional Nursing | ISSN: 2639-568

Journal Of Protein Research \& Bioinformatics

Journal Of Psychiatry Depression \& Anxiety | ISSN: 2573-0150

Journal Of Pulmonary Medicine \& Respiratory Research | ISSN: 2573-0177

Journal Of Reproductive Medicine Gynaecology \& Obstetrics | ISSN: 2574-2574

Journal Of Stem Cells Research Development \& Therapy | ISSN: 2381-2060

Journal Of Surgery Current Trends \& Innovations | ISSN: 2578-7284

Journal Of Toxicology Current Research | ISSN: 2639-3735

Journal Of Translational Science And Research

Journal Of Vaccines Research \& Vaccination | ISSN: 2573-0193

Journal Of Virology \& Antivirals

Sports Medicine And Injury Care Journal | ISSN: 2689-8829

Trends In Anatomy \& Physiology | ISSN: 2640-7752

Submit Your Manuscript: https://www.heraldopenaccess.us/submit-manuscript 